\title{
Mild hyperphenylalaninemia: to treat or not to treat
}

\author{
Francjan J. van Spronsen
}

Received: 7 October 2010 /Revised: 20 December 2010 /Accepted: 14 January 2011 /Published online: 24 February 2011

(C) The Author(s) 2011. This article is published with open access at Springerlink.com

\begin{abstract}
One of the issues to be resolved in phenylketonuria is whether patients with mild hyperphenylalaninemia need treatment, or in other words, in what patients treatment needs to be started. Do patients need treatment when phenylalanine concentrations in blood are $>360 \mu \mathrm{mol} / \mathrm{L}$ or $>600 \mu \mathrm{mol} / \mathrm{L}$ ? This paper reviews the literature on the outcome of untreated patients with mild hyperphenylalaninemia to try to determine whether outcome is normal. The paper concludes that there is, in fact, only one paper that can be used to answer this question. Therefore, the question is whether we may rely on one paper to draw conclusions or whether more research is necessary to determine whether all patients with phenylalanine concentrations $>360 \mu \mathrm{mol} / \mathrm{L}$ or all patients with phenylalanine concentrations $>600 \mu \mathrm{mol} / \mathrm{L}$ require treatment.
\end{abstract}

\section{Introduction}

Notwithstanding the huge number of studies in phenylketonuria (PKU; MIM\# 216600), questions remain on the table. One of those questions is whether treatment of patients with mildly increased phenylalanine (Phe) concentrations is necessary. The question has been addressed for years (Berry et al. 1979; Cabalska et al. 1977; Güttler 1980; Lang et al. 1989; Levy et al. 1971) but without a clear answer.

Two recent studies showed clear variation in Phe concentration that prompted professionals to start treatment at (van Spronsen et al. 2009, Blau et al. 2010b). Those data show that Phe concentrations at which treatment is started

Communicated by: Nenad Blau

F. J. van Spronsen $(\bowtie)$

Beatrix Children's Hospital,

Groningen, Netherlands

e-mail: f.j.van.spronsen@bkk.azg.nl vary from some 200 to $600 \mu \mathrm{mol} / \mathrm{L}$ (van Spronsen et al. 2009, Blau et al. 2010b). The study of van Spronsen et al. (2009) reveals that of the 17 centers reporting on this issue, eight started at a Phe $>360 \mu \mathrm{mol} / \mathrm{L}$, whereas seven started at $P$ he between $400 \mu \mathrm{mol} / \mathrm{L}$ and $500 \mu \mathrm{mol} / \mathrm{L}$, and two at Phe of $600 \mu \mathrm{mol} / \mathrm{L}$. Blau et al. (2010b) reported a larger group of centers $(N=93)$. That study did not report the precise data, but $5 \%$ of participating centers reported starting at Phe concentrations $>200 \mu \mathrm{mol} / \mathrm{L}, 37 \%$ at $>$ $400 \mu \mathrm{mol} / \mathrm{L}, 28 \%$ at $>600 \mu \mathrm{mol} / \mathrm{L}$, and $24 \%$ answered otherwise, including at $>300 \mu \mathrm{mol} / \mathrm{L},>360 \mu \mathrm{mol} / \mathrm{L}$, and between 400 and $600 \mu \mathrm{mol} / \mathrm{L}$. These data clearly show a lack of consensus, evidencing the need for at least discussion on this issue. Issues relevant to answering this question are

1. How is mild hyperphenylalaninemia (mHPA) defined?

2. What is the outcome of untreated patients with blood Phe concentrations between 360 and $600 \mu \mathrm{mol} / \mathrm{L}$ ?

3. How sure are we about these outcome data?

4. How can we explain that a specific blood Phe concentration considered toxic in more severe degrees of phenylalanine hydroxylase (PAH) deficiency is nontoxic in mHPA?

5. What are the drawbacks of dietary treatment?

6. Does the decision to treat (or not to treat) change when possibilities of treatment do?

These questions are addressed within this report with the aim of deciding upon the issue of whether or not to treat individuals with mHPA.

\section{Definition mild hyperphenylalaninemia}

It makes sense to define patients with mHPA as not needing treatment. Suggested Phe concentrations to start treatment 
directly after having achieved diagnosis vary between 200 and $600 \mu \mathrm{mol} / \mathrm{L}$ (Blau et al. 2010b). In patients up to 10 12 years of age with PKU that are treated, suggested Phe concentrations are generally up to $360 \mu \mathrm{mol} / \mathrm{L}$ (van Spronsen and Burgard 2008). Normal Phe concentrations are up to $120 \mu \mathrm{mol} / \mathrm{L}$ (Blau et al. 2010a). So, if we accept that the definition of mHPA is the group of patients with abnormal Phe concentrations not needing treatment, this group at least includes patients with untreated Phe concentrations between 120 and $360 \mu \mathrm{mol} / \mathrm{L}$. The really important question is whether individuals with untreated Phe concentrations between 360 and $600 \mu \mathrm{mol} / \mathrm{L}$ should be included in the mHPA group.

If we define the Phe concentration at which we determine not to start treatment, we must decide on at least three issues: (1) How often may Phe concentrations be above this level before we conclude that this patient should be treated? (2) Do we take Phe concentrations into account during infections? (3) How frequent do we measure when patients are just being followed without treatment? For these three issues, there is hardly any literature to base ideas on.

When a specific Phe concentration is considered of clinical relevance in a particular patient, it is necessary to start treatment as soon as this concentration is reached. On the other hand, prescribing unnecessary treatment should be avoided. Therefore, one event of Phe concentration above that level seems too little to start treatment. However, a follow-up Phe above that level probably needs to be followed by treatment. In this light, it needs also to be considered that treatment also consists of follow-up and that follow-up may lead to a decreased strictness again of the treatment when Phe concentrations remain well within target range. Discussing the issue to take Phe concentrations into account when there is some short illness, we must take into consideration that the brain probably does not care about the condition responsible for the Phe concentration. So, excessive Phe concentrations during illness are as harmful to brain development as excessive Phe concentrations periods without illness. Without treatment, there may be large fluctuations of Phe concentrations that may be harmful (Arnold et al. 1998; Anastasoaie et al. 2008). Diet may decrease the amplitude of these fluctuations to some extent. Therefore, these periods of short illness needs to be taken into account. It seems impossible to have a frequency of blood sampling in infants whose Phe concentrations are well below the level at which treatment needs to be considered comparable to the frequency in infants in who almost each Phe level means a direct change in treatment. Therefore, a lower frequency of monitoring seems reasonable in such children.

Prevention of maternal PKU necessitates keeping Phe concentrations $<360 \mu \mathrm{mol} / \mathrm{L}$ (Koch et al. 2010). From experience from the USA, it is known that it is difficult to return to a diet when they have not been on diet for years. However, this refers to the situation of severe PKU rather than milder forms. At the same time, for a woman with Phe concentrations of some $500-600 \mu \mathrm{mol} / \mathrm{L}$ without treatment, it may really be hard achieving Phe concentrations $<360$ or even $240 \mu \mathrm{mol} / \mathrm{L}$ clearly before conception. Therefore, although there is no need for girls to be treated more strictly than boys, the consequences of lack of treatment for maternal PKU may be important for treating girls before they wish to bear children.

When we decide to start treatment after some time in a child who had previous Phe concentrations below the threshold required to start treatment but above the upper target treatment concentration at the same time, but who after some time has Phe values above the threshold to required start treatment (and above the target treatment concentration), we must consider that this might mean that the patient required treatment from early on.

It might be questioned whether we can define mHPA using the tolerance of Phe or the genotype rather than the Phe concentrations in the untreated condition. Children followed because of mHPA will consume a more or less normal natural protein intake, so that tolerance cannot be used. DNA mutations may give clarity about the clinical phenotype (Guldberg et al. 1998). Therefore, when we decide on the in vivo definition of MHPA, we can use the DNA genotype.

\section{The outcome of untreated patients with blood phenylalanine concentrations between 360 and $600 \mu \mathrm{mol} / \mathrm{L}$}

When IQ data are discussed, the Phe range that has been considered harmless is up to $400 \mu \mathrm{mol} / \mathrm{L}$ (Costello et al. 1994), $600 \mu \mathrm{mol} / \mathrm{L}$ (Weglage et al. 1996a; Güttler 1980; Smith et al. 2000), $720 \mu \mathrm{mol} / \mathrm{L}$ (Levy et al. 1971), $900 \mu \mathrm{mol} / \mathrm{L}$ (Berry et al. 1979), or even 1,200 $\mu \mathrm{mol} / \mathrm{L}$ (Lang et al. 1989). Costello et al's. data can be interpreted in more than one way. It is clear that the group of six patients with untreated Phe concentrations $<400 \mu \mathrm{mol} / \mathrm{L}$ had an IQ just above 100, the group of 11 patients with concentrations between 400 and $500 \mu \mathrm{mol} / \mathrm{L}$ had an IQ of 0.5 standard deviations (SD) below 100, and the group of seven patients with untreated concentrations $>500 \mu \mathrm{mol} / \mathrm{L}$ had an SD score of -1.1 below 100. However, if statistical analysis had been performed, the differences probably would have proven to be statistically insignificant due to the small numbers and relatively large variation. Still, based on these figures, the British Medical Research Council for PKU in 1993 advised that patients should be treated when Phe concentration reach $400 \mu \mathrm{mol} / \mathrm{L}$ (Medical Research 
Council 1993), and the guidelines have not been changed since then.

When neuropsychological data are discussed, there are six research papers on this issue. Weglage produced two articles on this issue in 1996 and one in 2001 (Weglage et al. 1996a; Weglage et al. 1996b; Weglage et al. 2001). All their papers on patients with untreated Phe concentrations between 360 and $600 \mu \mathrm{mol} / \mathrm{L}$ showed a normal outcome with regard to their neuropsychological data. Diamond et al. studied patients with untreated Phe concentrations between 360 and $600 \mu \mathrm{mol} / \mathrm{L}$ showing abnormalities on certain executive functions (Diamond et al. 1997). In 2005, Gassio et al. found abnormalities on specific executive functions at Phe concentrations even $<360 \mu \mathrm{mol} / \mathrm{L}$ (Gassió et al. 2005). This is in contrast to data of Smith et al. that showed normal neuropsychological outcome at Phe concentrations up to $600 \mu \mathrm{mol} / \mathrm{L}$ (Smith et al. 2000). What can we conclude from this? First, the question is whether we can use IQ data. Even in treated PKU, IQ is not that abnormal when patients are not that well treated. In the past, in treated PKU, IQ was said to be normal even at Phe concentrations $<1,300 \mu \mathrm{mol} / \mathrm{L}$ and $<900 \mu \mathrm{mol} / \mathrm{L}$ (Holtzman et al. 1986; Scriver et al. 1989). At the same time, we now know that these patientseven though having a normal IQ - had an abnormal school career and also had neuropsychological problems. So, IQ data may not be that helpful to determine whether or not to treat patients with mHPA.

When we look at the neuropsychological tests, there are some peculiar findings should be discussed. For example, Diamond et al. (1997) showed some abnormalities at Phe concentrations between 360 and $600 \mu \mathrm{mol} / \mathrm{L}$. That means that the higher the Phe concentrations were within this range, the more the neuropsychological tests showed abnormal results. However, at the same time, as a group, these patients showed results comparable with the normal population. The results of Smith et al. are said to be normal (Smith et al. 2000), but they studied patients with Phe concentrations between 100 and $600 \mu \mathrm{mol} / \mathrm{L}$ with a mean of $315 \mu \mathrm{mol} / \mathrm{L}$ Therefore, these data cannot be used to answer the questions presented here. Weglage et al. reported in 1996 that there were no problems in their group of patients with Phe concentrations between 360 and $600 \mu \mathrm{mol} / \mathrm{L}$ (Weglage et al. 1996a; Weglage et al. 1996b). However, their paper of 2001 reported that in the same group of patients, only 10 of the 28 had untreated Phe concentrations between 360 and $600 \mu \mathrm{mol} / \mathrm{L}$ (Weglage et al. 1996a; Weglage et al. 1996b; Weglage et al. 2001). In contrast, the data of Weglage et al. (2001) only concerned patients with untreated Phe concentrations between 360 and $600 \mu \mathrm{mol} / \mathrm{L}$ (Weglage et al. 2001). Data of that study showed really normal neuropsychological outcomes. Data from Gassio et al. showed that Phe concentrations, which are more or less to be considered safe in treated PKU patients (below $360 \mu \mathrm{mol} / \mathrm{L}$ ), are not that safe, and, therefore, at least did not support the data of Weglage et al. (Gassió et al. 2005, Weglage et al. 2001). So, when data on IQ cannot be used, and some of the studies reporting on neuropsychological outcome cannot be judged that easily, there are at least a few reasons for some uncertainty. Therefore, the question is whether we can determine conclusions based on the one study by Weglage et al. (2001).

\section{Certainty of outcome data in PKU}

In the previous paragraph, we show that it is not that easy to decide whether or not to treat a specific group of patients based on the one (although very good) paper of Weglage et al. (2001). Next, some examples are shown in PKU literature showing that deciding on data of one or two papers on important issues and which have not been substantiated by other papers has led to incorrect treatment strategy. There is ongoing discussion to determine the safe Phe concentration at various ages in treated patients. In the past, studies showed that the Phe concentration was safe when $<1,300 \mu \mathrm{mol} / \mathrm{L}$ (Scriver et al. 1989). Other studies showed that the safe Phe concentrations were $<900 \mu \mathrm{mol} / \mathrm{L}$ (Holtzman et al. 1986). In recent years, advice on the upper target Phe concentration during childhood decreased to 600, $480,360,300$, or even $240 \mu \mathrm{mol} / \mathrm{L}$ (van Spronsen and Burgard 2008). Another example is uncertainty as to the age at which treatment can be stopped safely. Initially, a large number of clinics in North America discontinued dietary treatment during the first decade of life (Azen et al. 1991). Such ideas on the possibility of discontinuing treatment were based on the belief that myelination, in particular, was complete by this age and not susceptible to damage by high Phe concentrations and that abandonment of the diet was consequently unlikely to be harmful. In addition, older children with poor dietary adherence did not become obviously disabled.

Discontinuing the diet at age 10 years in Scotland resulted in poorer performance in cognitive and motor function tests for patients with PKU relative to their agematched non-PKU peers at a median age of 20 years, although cognitive function per se did not decline (Griffiths et al. 1995). Neuropsychological studies (Huijbregts et al. 2002, Huijbregts et al. 2003, Azen et al. 1991) showed that the treatment at least should continue after 12 years of age. For later age, the only thing we know for sure is that we do not know when-or whether at al-to stop treatment. Studies comparing results between German and French centers showed evidence that longer treatment was important (Burgard et al. 1997). Nowadays, centers advise treatment for life (van Spronsen and Burgard 2008). Of 
course, this applies to male patients with PKU, as women with PKU are strongly advised not to discontinue treatment before childbearing age has been passed.

\section{Difference between $360 \mu \mathrm{mol} / \mathrm{L}$ and $360 \mu \mathrm{mol} / \mathrm{L}$}

Explaining that a Phe concentration $>360 \mu \mathrm{mol} / \mathrm{L}$ is unsafe in one patient with classical PKU and safe in the other patient with mild PKU is hard when there is no additional explanation for vulnerability, or the lack of it, in specific groups of patients. There may be at least two possible reasons for this. One might be a difference in Phe to tyrosine ratio between these groups. At least two publications suggest that apart from the absolute Phe concentration, the ratio of Phe to tyrosine might be of important additional value in explaining and interpreting neurocognitive outcome (Luciana et al. 2001, Sharman et al. 2010). It may be expected that in milder PAH deficiencies not only is Phe not that high, but tyrosine also is higher, so that the ratio is in better balance. However, neither of these studies have paid attention to timing of the sampling of blood to measure tyrosine concentrations in PKU patients. Tyrosine concentrations are known to show large diurnal variations (van Spronsen et al. 1993, 1996). Therefore, such studies can only be reliable when the moment of blood sampling is carefully specified, taking the moment of intake of tyrosine enriched amino acid mixtures into account as well.

Another explanation, suggested by studies of Arnold et al. and Anastasoaie et al., is that the variation in the blood Phe concentration rather than the absolute Phe concentration may be of importance for neurocognitive development (Arnold et al. 1998; Anastasoaie et al. 2008). Due to the fact that in mHPA the rest activity of PAH is larger, patients with a larger amount of functional enzyme capacity will be able to metabolize larger amounts of Phe in a way that there is a smaller fluctuation of the blood Phe concentration. Therefore, in mHPA, variations in Phe concentrations may be expected to be smaller, and following the hypothesis of Arnold et al. (1998) and Anastasoaie et al. (2008), the smaller these variations in Phe, the better the outcome.

\section{Drawbacks of the dietary treatment}

Notwithstanding the enormous improvement in neurocognitive outcome during dietary treatment, it is fair to state that dietary treatment has its drawbacks. It may influence growth, as there are differences in growth patterns between various groups/countries (Verkerk et al. 1994; Hoeksma et al. 2005; Acosta et al. 1998; Schaefer et al. 1994; Dobbelaere et al. 2003). It clearly may result in deficiencies of, for example, long-chain unsaturated fatty acids and vitamin $\mathrm{B}_{12}$ (Hanley et al. 1993; Hvas et al. 2006; Huemer et al. 2008). It results in decreased bone density (Zeman et al. 1999, Modan-Moses et al. 2007). Patients with PKU have less self-confidence, may have some peculiar behavior, have less long -asting, stable relationships, experience anxiety and depression (Simon et al. 2008, Smith et al. 1988, Ris et al. 1994 of 1997, Pietz et al. 1997, Waisbren and Levy 1991, Weglage et al. 1992, Hendrikx et al. 1994). At this time, we do not know whether this is due to stringent treatment, to little treatment, or to PKU itself.

\section{Influence of other treatment options on the decision to treat or not to treat}

It is fair to state that the easier the treatment, the more likely patients will be to take the treatment. This would implicate that the possibility of treatment strategies that are less burdensome than the stringent diet (for review, see van Spronsen and Enns 2010) may result in an increase in patients who are willing to be treated. However, that assumption is not correct. When treatment really is unnecessary with a certain treatment modality, this conclusion cannot be changed just because other treatment modalities become available.

\section{Conclusion}

At this time, we do not have enough data to prove or deny the hypothesis that patients who-without treatment-have Phe concentrations between 360 and $600 \mu \mathrm{mol} / \mathrm{L}$ can remain without treatment. Further studies are therefore warranted to solve this issue. On the one hand, we must treat when necessary, but on the other hand, we must prevent instituting treatment when it is unnecessary in this group of individuals, as we may unnecessarily make them feel as if they are patients. Treatment may not only may make life unnecessarily difficult for those patients and their families, it may also induce problems with, e.g., job, career, health insurance, as well as create an unnecessarily negative balance in the health care system.

Competing interest The author declares that he is a member of several advisory boards of Nutricia and Merck Serono, and has received grants from, and is an advisor for, Merck Serono, and has received a grant from Nutricia.

Open Access This article is distributed under the terms of the Creative Commons Attribution Noncommercial License which permits any noncommercial use, distribution, and reproduction in any medium, provided the original author(s) and source are credited. 


\section{References}

Acosta PB, Yannicelli S, Marriage B (1998) Nutrient intake and growth of infants with phenylketonuria undergoing therapy. J Pediatr Gastroenterol Nutr 27:287-291

Anastasoaie V, Kurzius L, Forbes P, Waisbren S (2008) Stability of blood phenylalanine levels and IQ in children with phenylketonuria. Mol Genet Metab 95:17-20

Arnold GL, Kramer BM, Kirby RS et al (1998) Factors affecting cognitive, motor, behavioral and executive functioning in children with phenylketonuria. Acta Paediatr 87:565-570

Azen CG, Koch R, Friedman EG et al (1991) Intellectual development in 12-year-old children treated for phenylketonuria. Am J Dis Child 145:35-39

Berry HK, O’Grady DJ, Perlmutter LJ, Bofinger MK (1979) Intellectual development and academic achievement of children treated early for phenylketonuria. Dev Med Child Neurol 21:311-320

Blau N, van Spronsen FJ, Levy HL (2010a). Phenylketonuria. Lancet, accepted

Blau N, Belanger-Quintana A, Demirkol M et al (2010b) Management of phenylketonuria in Europe: survey results from 19 countries. Mol Genet Metab 99:109-115

Burgard P, Rey F, Rupp A, Abadie V, Rey J (1997) Neuropsychologic functions of early treated patients with phenylketonuria, on and off diet: results of a cross-national and cross-sectional study. Pediatr Res 41:368-374

Cabalska B, Duczyńska N, Borzymowska J, Zorska K, Koślacz-Folga A, Bozkowa K (1977) Termination of dietary treatment in phenylketonuria. Eur J Pediatr 126:253-262

Costello PM, Beasley MG, Tillotson SL, Smith I (1994) Intelligence in mild atypical phenylketonuria. Eur J Pediatr 153:260-263

Diamond A, Prevor MB, Callender G, Druin DP (1997) Prefrontal cortex cognitive deficits in children treated early and continuously for PKU. Monogr Soc Res Child Dev 62(i-v):1-208

Dobbelaere D, Michaud L, Debrabander A et al (2003) Evaluation of nutritional status and pathophysiology of growth retardation in patients with phenylketonuria. J Inherit Metab Dis 26:1-11

Gassió R, Artuch R, Vilaseca MA et al (2005) Cognitive functions in classic phenylketonuria and mild hyperphenylalaninaemia: experience in a paediatric population. Dev Med Child Neurol 47:443448

Griffiths P, Paterson L, Harvie A (1995) Neuropsychological effects of subsequent exposure to phenylalanine in adolescents and young adults with early-treated phenylketonuria. J Intellect Disabil Res 39:365-372

Guldberg P, Rey F, Zschocke J et al (1998) A European multicenter study of phenylalanine hydroxylase deficiency: classification of 105 mutations and a general system for genotype-based prediction of metabolic phenotype. Am J Hum Genet 63:71-79

Güttler F (1980) Hyperphenylalaninemia: diagnosis and classification of the various types of phenylalanine hydroxylase deficiency in childhood. Acta Paediatr Scand Suppl 280:1-80

Hanley WB, Feigenbaum A, Clarke JT, Schoonheyt W, Austin V (1993) Vitamin B12 deficiency in adolescents and young adults with phenylketonuria. Lancet 342:997

Hendrikx MM, van der Schot LW, Slijper FM, Huisman J, Kalverboer AF (1994) Phenylketonuria and some aspects of emotional development. Eur J Pediatr 153:832-835

Hoeksma M, Van Rijn M, Verkerk PH, et al. (2005) The intake of total protein, natural protein and protein substitute and growth of height and head circumference in Dutch infants with phenylketonuria. J Inherit Metab Dis 28(6):845-54.

Holtzman NA, Kronmal RA, van Doorninck W, Azen C, Koch R (1986) Effect of age at loss of dietary control on intellectual performance and behavior of children with phenylketonuria. $\mathrm{N}$ Engl J Med 314:593-598

Huemer M, Födinger M, Bodamer OA et al (2008) Total homocysteine, B-vitamins and genetic polymorphisms in patients with classical phenylketonuria. Mol Genet Metab 94:46-51

Huijbregts SC, de Sonneville LM, Licht R, van Spronsen FJ, Verkerk PH, Sergeant JA (2002) Sustained attention and inhibition of cognitive interference in treated phenylketonuria: associations with concurrent and lifetime phenylalanine concentrations. Neuropsychologia 40:7-15

Huijbregts SC, de Sonneville LM, Van Spronsen FJ et al (2003) Motor function under lower and higher controlled processing demands in early and continuously treated phenylketonuria. Neuropsychology 17:369-379

Hvas AM, Nexo E, Nielsen JB (2006) Vitamin B12 and vitamin B6 supplementation is needed among adults with phenylketonuria (PKU). J Inherit Metab Dis 29:47-53

Koch R, Trefz F, Waisbren S (2010) Psychosocial issues and outcomes in maternal PKU. Mol Genet Metab 99(Suppl 1):S68-S74

Lang MJ, Koch R, Fishler K, Baker R (1989) Nonphenylketonuric hyperphenylalaninemia. Am J Dis Child 143:1464-1466

Levy HL, Shih VE, Karolkewicz V et al (1971) Persistent mild hyperphenylalaninemia in the untreated state. A prospective study. N Engl J Med 285:424-429

Luciana M, Sullivan J, Nelson CA (2001) Associations between phenylalanine-to-tyrosine ratios and performance on tests of neuropsychological function in adolescents treated early and continuously for phenylketonuria. Child Dev 72:1637-1652

Medical Research Council for Phenylketonuria (1993) Recommendations on the dietary management of phenylketonuria. Report of medical research council working party on phenylketonuria. Arch Dis Child 68:426-427

Modan-Moses D, Vered I, Schwartz G et al (2007) Peak bone mass in patients with phenylketonuria. J Inherit Metab Dis 30:202-208

Pietz J, Fätkenheuer B, Burgard P, Armbruster M, Esser G, Schmidt H (1997) Psychiatric disorders in adult patients with early-treated phenylketonuria. Pediatrics 99:345-350

Ris MD, Williams SE, Hunt MM, Berry HK, Leslie N (1994) Earlytreated phenylketonuria: adult neuropsychologic outcome. J Pediatr 124:388-392

Schaefer F, Burgard P, Bazler U et al (1994) Growth and skeletal maturation in children with phenylketonuria. Acta Paediatr 83:534-541

Scriver CR, Kaufman S, Woo SLC (1989) The hyperphenylalaninemias. In: Scriver CR, Beaudet AL, Sly WS, Valle D (eds) The metabolic basis of inherited disease, 6th edn., pp 495-546

Sharman R, Sullivan K, Young R, McGill J (2010) A preliminary investigation of the role of the phenylalanine:tyrosine ratio in children with early and continuously treated phenylketonuria: toward identification of "safe" levels. Dev Neuropsychol 35:57-65

Simon E, Schwarz M, Roos J et al (2008) Evaluation of quality of life and description of the sociodemographic state in adolescent and young adult patients with phenylketonuria (PKU). Health Qual Life Outcomes 26:25

Smith I, Beasley MG, Wolff OH, Ades AE (1988) Behavior disturbance in 8-year-old children with early treated phenylketonuria. Report from the MRC/DHSS Phenylketonuria Register. J Pediatr 112:403-408

Smith ML, Saltzman J, Klim P, Hanley WB, Feigenbaum A, Clarke JT (2000) Neuropsychological function in mild hyperphenylalaninemia. Am J Ment Retard 105:69-80

van Spronsen FJ, Ahring KK, Gizewska M (2009) PKU-what is daily practice in various centres in Europe? Data from a questionnaire by the scientific advisory committee of the European Society of Phenylketonuria and Allied Disorders. J Inherit Metab Dis 32:5864 
van Spronsen FJ, Burgard P (2008) The truth of treating patients with phenylketonuria after childhood: the need for a new guideline. J Inherit Metab Dis 31:673-679

Van Spronsen FJ, Enns GM (2010) Future treatment strategies in phenylketonuria. Mol Genet Metab Suppl 99:90-95

van Spronsen FJ, van Rijn M, van Dijk T et al (1993) Plasma phenylalanine and tyrosine responses to different nutritional conditions (fasting/postprandial) in patients with phenylketonuria: effect of sample timing. Pediatrics 92:570-573

van Spronsen FJ, van Dijk T, Smit GP, van Rijn M, Reijngoud DJ, Berger R, Heymans HS (1996) Phenylketonuria: plasma phenylalanine responses to different distributions of the daily phenylalanine allowance over the day. Pediatrics 97:839-844

Verkerk PH, van Spronsen FJ, Smit GP, Sengers RC (1994) Impaired prenatal and postnatal growth in Dutch patients with phenylketonuria. The National PKU Steering Committee. Arch Dis Child $71: 114-118$
Waisbren SE, Levy HL (1991) Agoraphobia in phenylketonuria. J Inherit Metab Dis 14:755-764

Weglage J, Fünders B, Wilken B et al (1992) Psychological and social findings in adolescents with phenylketonuria. Eur J Pediatr 151:522-525

Weglage J, Ullrich K, Pietsch M, Fünders B, Zass R, Koch HG (1996a) Untreated non-phenylketonuric-hyperphenylalaninaemia: intellectual and neurological outcome. Eur J Pediatr 155(Suppl 1): S26-S28

Weglage J, Schmidt E, Fünders B, Pietsch M, Ullrich K (1996b) Sustained attention in untreated non-PKU-hyperphenylalaninemia. J Clin Exp Neuropsychol 18:343-348

Weglage J, Pietsch M, Feldmann R et al (2001) Normal clinical outcome in untreated subjects with mild hyperphenylalaninemia. Pediatr Res 49:532-536

Zeman J, Bayer M, Stepán J (1999) Bone mineral density in patients with phenylketonuria. Acta Paediatr 88:1348-1351 